\title{
Response of Reinforced Concrete Slabs Strengthened with CFRP
}

\author{
Omar Al-Ghazawi ${ }^{1}$ and Rajai Z. Al-Rousan ${ }^{2, *}$ \\ ${ }^{I}$ Department of Civil Engineering, Al-Ahliyya Amman University, Jordan \\ ${ }^{2}$ Department of Civil Engineering, Jordan University of Science \& Technology, Jordan
}

Received 29 October 2020; Accepted 15 December 2020

\begin{abstract}
Seven reinforced concrete (RC) slabs, with dimensions of $2440 \times 600 \times 125 \mathrm{~mm}$, were designed and modeled utilizing the nonlinear finite element analysis (NLFEA) method. The modeled specimens were equipped with several strengthening configurations, aiming at exploring the impact of the strengthening technique on the RC slabs, particularly those not adequately reinforced. The attained NLFEA's results explicitly affirmed that carbon fiber reinforced polymer (CFRP) materials to strengthen the poorly-strengthened RC slabs far improved the slabs' flexural strength capacity and decreased the ductility, as well. It was found that this impact was more apparent when the number of CFRP strips was raised. That was so evident from the obtained response curves of load-deflection and load-strain. This study findings have concluded that using the CFRP laminates to strengthen the RC slabs is considered highly advantageous as long it enhances the slab's flexural capacity without affecting the mode of failure.
\end{abstract}

Keywords: CFRP, Strengthening, Slabs, Flexural Strength Capacity, Ductile, NLFEA.

\section{Introduction}

In recent years, the carbon fiber reinforced polymer (CFRP) composites have been widely utilized to rehabilitate and strengthen weak and harmed RC structures [1-6]. However, this technique has not been used in deficient RC slabs as much. Strengthening and repairing RC slabs, the one-way and the two-way types, with CFRP laminates have not received much of the researchers' attention. The available information reveals that RC slabs do not need a much fiber reinforced polymer (FRP) laminate as other types of structures to obtain the same results [7-11].

The impact of the CFRP laminates on the behavior of RC slabs is investigated by Arduini et al. [12]. Simply supported twenty-six RC slabs were built; some were strengthened with overhang laminates, while the other remained un-strengthened. The cross-sectional area of the CFRP laminates and the steel reinforcement quantity were varied upon the testing process. As a result, various modes of failure occurred, namely: concrete crushing, concrete shear, CFRP peeling, and CFRP rupture [12]. From their side, Limam et al. [13] examined the influence of the strengthening techniqueusing CFRP laminates on the performance of two-way RC slabs.The obtained experimental results indicated that the most two common modes of failure were: de-bonding and concrete peeling [13].

Ebead et al. [14] conducted experimental research to investigate the impact of the material's type of FRP laminates (carbon FRP strips and glass FRP laminates) on the performance of the two-way RC slabs. Some of the study samples had been strengthened in punching shear, while the others were strengthened in flexure, while there

*E-mail address: rzalrousan@gmail.com

ISSN: 1791-2377 @ 2020 School of Science, IHU. All rights reserved. doi:10.25103/jestr.136.17 were specimens left un-strengthened as a reference. The study results indicated that the strengthened two-way RC slabs' flexural capacity was higher by almost $35.5 \%$ than the un-strengthened reference specimen [14]. Also, Tan et al. [15] studied the influence of the CFRP composites materials, when bonded externally, on the RC slabs' flexural performance. The results showed that the externally-bonded CFRP laminates enhanced the slabs' flexural capacity, minimized the width of the cracks, and reduced deflections, as well [15]. Nevertheless, most of the research has focused only on how to improve the flexural capacity, omitting the importance of the structural ductility [7-15] as an early indicator of imminent failures. It is worth pointing out that the reinforcing steel's yielding causes the failure of the structure that are weakly reinforced with steel.

Additionally, when the exerted load rises, a significant deformation state occurs without affecting the loadcarrying capacity; consequently, the concrete crushes when the load reaches its ultimate level. This form of failure is ductile in nature, and it indicates an insufficient percentage of the installed steel reinforcement. The ACI 318-08 [16] code indicates that the condition of tension control is determined by the ultimate strain developed in the tension steel, with a value higher than $5000 \mu \varepsilon$. Therefore, the reinforcement ratio is so important to be adequately set to avail a satisfactory ductility. The study in hand utilizes the ANSYS software to investigate the simulated-by-NLFEA, one-way RC slabs, strengthened with CFRP composites [17].

\section{Finite Element Analysis}

a) Specimens details

The experimental study samples consisted of seven simulated-by-NLFEA RC slabs, with dimensions of 
$2440 \times 600 \times 125 \mathrm{~mm}$. The compressive strength of the concrete content, aged 28 days, was $55 \mathrm{MPa}$. The flexural and shear steel reinforcement was designed using steel of Grade 60to make sure that slabs failed in flexural (under-reinforced condition). The slab reinforcement included 54 bars in the long direction, and \#3 bars in the short direction, distanced $300 \mathrm{~mm}$ of spacing, center to center. Figure 1 illustrates the slabs' standard cross-section, details of reinforcement, and the configurations of the CFRP.

\section{b) Element types and material properties}

Concrete is known for its semi-brittle nature, and it exhibits different behaviors in tension and compression. The SOLID65 element was used to model the concrete. This element is advantageous for its ability to predict linear and nonlinear behavior of the material; and its effectiveness in 3D cracking, plastic deformation, crushing, and creep. To specify the criterion of concrete's failure, resulting from a state of multi-axial stress, it is essential to monitor the compressive and the ultimate tensile capacities [18]. The concrete exhibits a linear elastic stress-strain behavior in tension, while it is not linear in compression.

The concrete cracks first appeared when the tensile stress became higher than the ultimate tensile strength, in the lowest fiber, at mid-span. The cracking face's state is specified by the shear transfer coefficient $(t)$, with a range of 0.0 (smooth, no shear transfer) to 1.0 (rough, full shear transfer) [17]. The majority of the researches preferred to set the range of $(\mathrm{t})$ between 0.05 and 0.25 [19]. In this study, the following values were set: 0.2 for $(t)$ and $55 \mathrm{MPa}$ for the concrete's compressive strength at the age of 28 days. Besides, the young's modulus (Ec) was $35063 \mathrm{MPa}$, and the Poisson's ratio was 0.17 .

When the behavior is elastic-plastic, reinforcing with steel is not distinguished in tension or compression. The reinforcing steel was devised using the LINK8 element, with a Poisson's ratio 0.3 , the elastic modulus of $200 \mathrm{GPa}$, and yield stress of $410 \mathrm{MPa}$. Besides, the SOLID45 element was utilized to devise the steel plates for supports and loading, having an identical behavior to steel reinforcement.

The SOLID46 element was also used to model both the CFRP laminates (with a thickness of $0.165 \mathrm{~mm}$ ) and the epoxy layer (with a thickness of $0.343 \mathrm{~m}$ ). It should be mentioned that this element has been chosen in this study because it can model numerous different CFRP layer configurations, 250 of them max., in various directions. The materials of the CFRP laminates and the epoxy were presumed orthotropic, where the CFRP's tensile strength was 4272, and the epoxy strength was $55 \mathrm{MPa}$. The elastic modulus of the CFRP was 228 , and for epoxy was $30 \mathrm{GPa}$. Additionally, the ultimate tensile strain in CFRP was 0.0167 and for epoxy was 0.018 . All were in the direction of fibers. The CFRP's elastic modulus was presumed one millionth (106 ) of the modules in the fiber's direction in the other perpendicular directions. Also, the stress-strain behavior of both the CFRP and epoxy were presumed linear elastic. Figure 2 shows the stress-strain curves for concrete, steel reinforcement, CFRP composite, and epoxy.

c) Modeling methodology and Nonlinear solution and failure criteria

Based on the RC slab's symmetry and to avoid wasting time and computer resources, only one-quarter of a slab model had been put to analysis, paying good attention to properly account for the boundary conditions, as illustrated in Figure 3.
It is necessary to conduct a convergence study to define theadequate mesh density of the slab's analyzed portion. In addition, the concrete-FRP bond was presumed to be fully adhered. The ANSYS software was used to break up the total load to less-sized increments of load. At each increment's end,the Newton Raphson equilibrium iterations were utilized to run a convergence with a tolerance margin of 0.001 . Within the time of concrete cracking, the load increment was reduced, gradually. The models experienced a failure after divergence of the load increment of $0.0045 \mathrm{kN}$.

\section{Results and Discussion}

\section{a) Validation Process}

Figure 4 shows the load versus mid-span deflection curves obtained from the experimental testing [20] and the NLFEA for the control slabs and strengthened slab with one strip. Figure 4 reveals that the obtained load-deflection responses for each slab from the NLFEA were in excellent agreement with the experimental test results. Validation of the NLFEA results with the experimental test results provides substantial benefits in reducing the experiment's cost and time. Also, the NLFEA can analyze and model any configuration of CFRP strengthening.

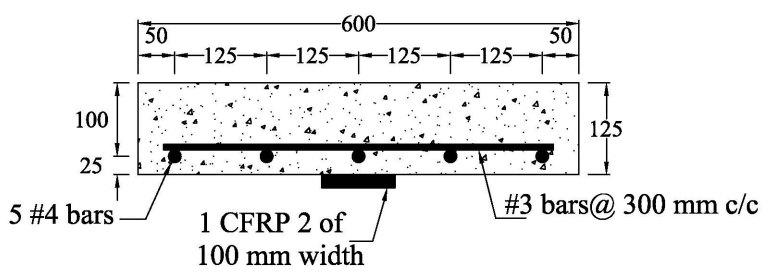

1 CFRP of $100 \mathrm{~mm}$ width

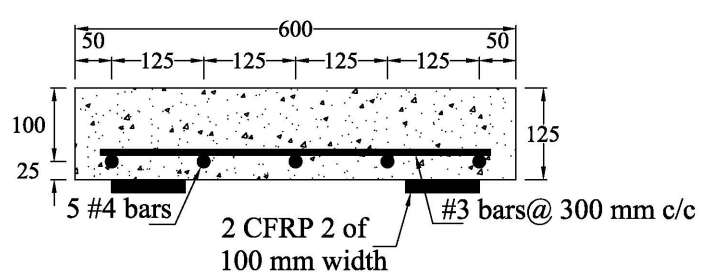

2 CFRP of $100 \mathrm{~mm}$ width

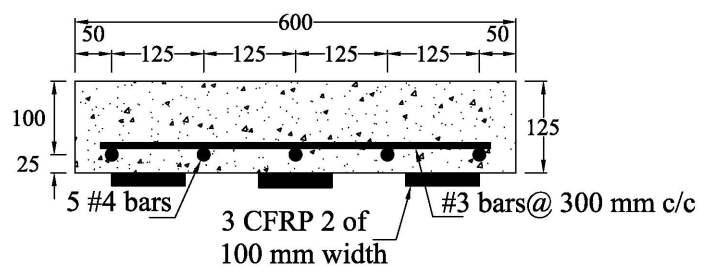

3 CFRP of $100 \mathrm{~mm}$ width

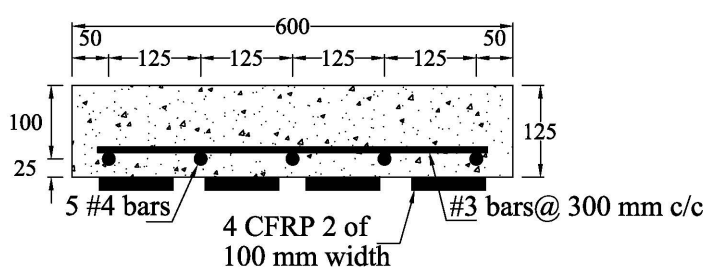

4 CFRP of $100 \mathrm{~mm}$ width 


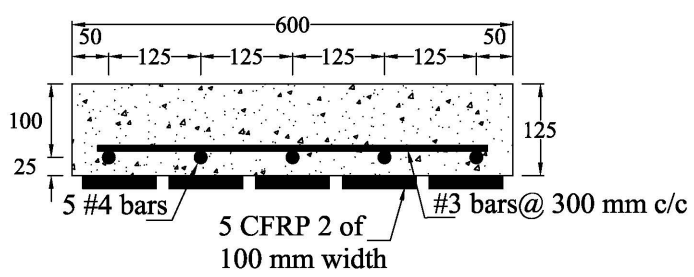

5 CFRP of $100 \mathrm{~mm}$ width

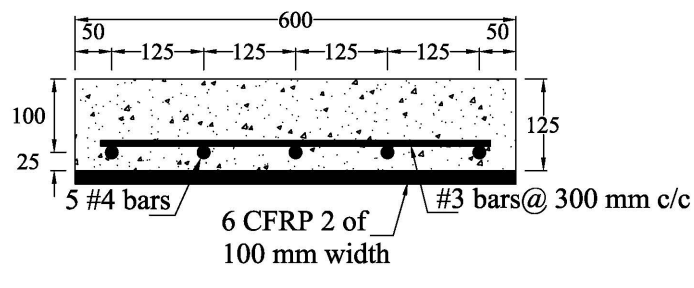

6 CFRP of $100 \mathrm{~mm}$ width

Fig. 1. NLFEA CFRP configurations

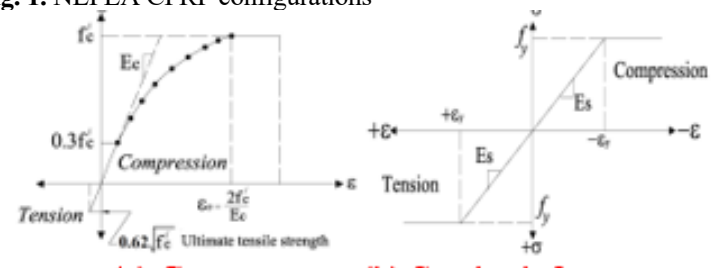

(a) Concrete

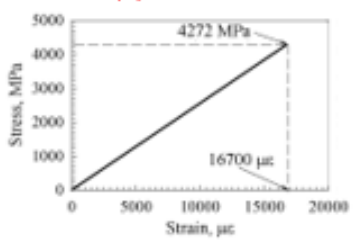

(c) CFRP composite

(b) Steel reinforcement

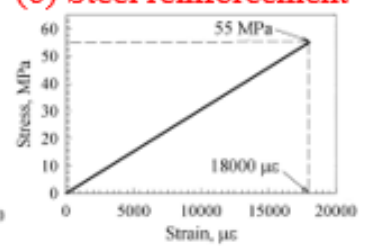

(d) Epoxy

Fig. 2. Stress-strain curves

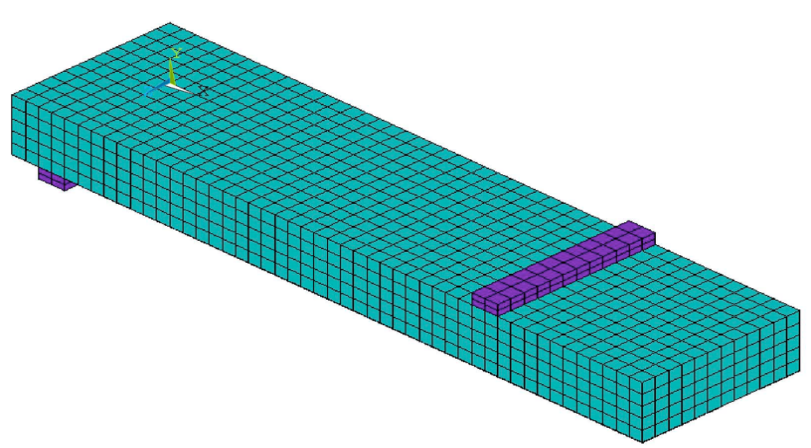

Fig. 3. Typical finite element meshing of the quarter of the slabs

\section{b) Load-Deflection Response}

The specimens' performance was examined by inspecting the load-deflection curves. Post concrete cracking beneath the neutral axis, the load versus mid-span deflection curve stayed linear up until the tensile steel yielding point. After that point, the steel yielded, while the beam kept resisting the continuously rising load, with a much less load rate, till the concrete crushed in the region of compression. This part of the curve was almost flat (horizontal), with a slight rise in the load. However, the rise was greater in deflection, which occurred at a load than the ultimate level. Figure 5 shows the load versus mid-span deflection curves for the control slabs and strengthened modeled slabs.

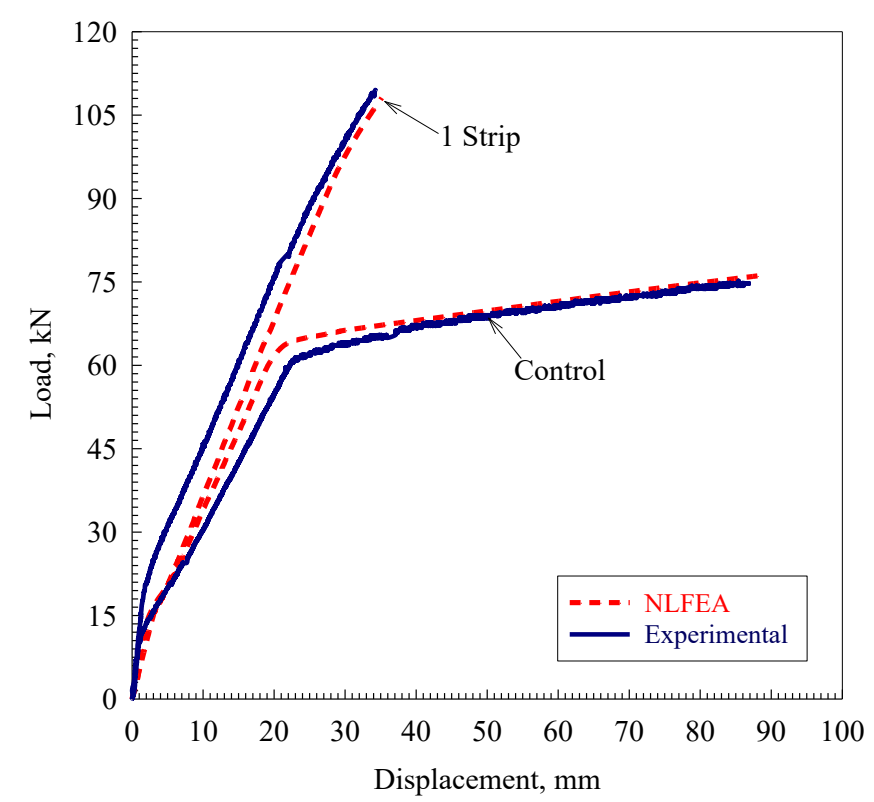

Fig. 4. Load deflection responses for the validation process

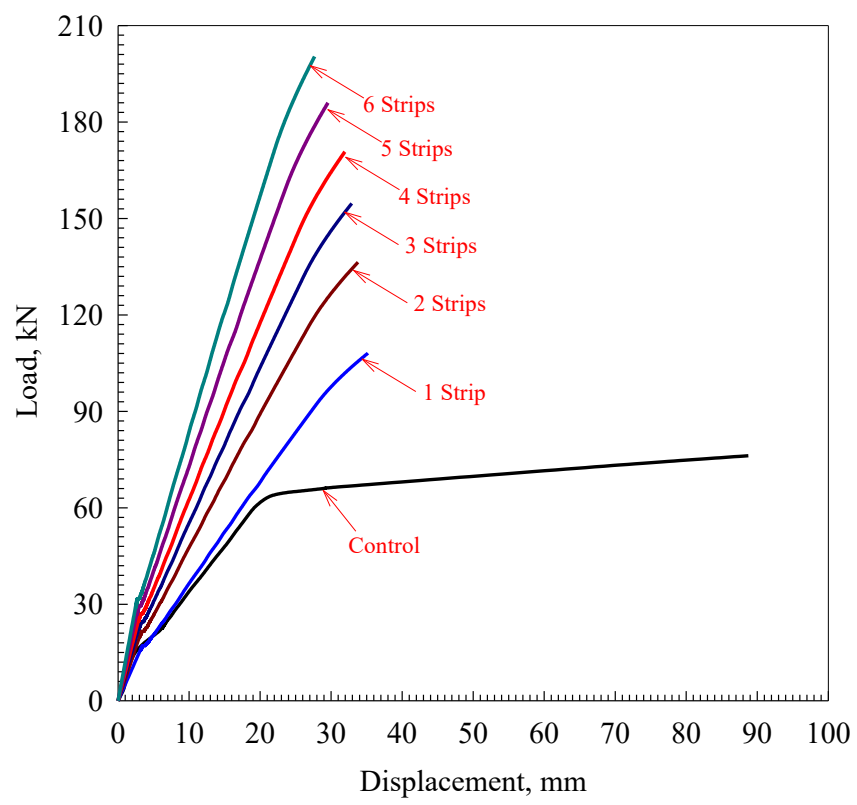

Fig. 5. Load deflection responses

For the strengthened slabs with 6 strips, 5 strips, 4 strips, 3 strips, 2 strips, and 1 strip, the ultimate loads were 210.4, $195.3,179.3,162.4,143.2$, and $108.1 \mathrm{kN}$, respectively, which represent an increase in the ultimate load with respect to the control slab of $176 \%, 156 \%, 135 \%, 113 \%, 88 \%$, and $42 \%$, respectively, as shown in Table 1 .

Table 1. Anlsysis results at failure

\begin{tabular}{c|c|c}
\hline CFRP configuration & Ultimate load, $\mathbf{k N}$ & Ultimate deflection, $\mathbf{m m}$ \\
\hline Control & 76.2 & 88.7 \\
1 strip & 108.1 & 35.2
\end{tabular}




\begin{tabular}{l|l|r}
2 strips & 136.4 & 33.8 \\
3 strips & 154.7 & 32.9 \\
4 strips & 170.8 & 31.9 \\
5 strips & 186.0 & 29.6 \\
6 strips & 200.4 & 27.7
\end{tabular}

The stiffness is defined as the slope of the linear part of the load-deflection response. The stiffness for strengthened slabs with 6 strips, 5 strips, 4 strips, 3 strips, 2 strips, and 1 strip was $11.4 \mathrm{kN} / \mathrm{mm}, 9.9 \mathrm{kN} / \mathrm{mm}, 8.4 \mathrm{kN} / \mathrm{mm}, 7.4 \mathrm{kN} / \mathrm{mm}$,
$6.3 \mathrm{kN} / \mathrm{mm}$, and $4.8 \mathrm{kN} / \mathrm{mm}$, respectively, which represent an increase in the stiffness with respect to the control slab of $200 \%, 162 \%, 122 \%, 96 \%, 68 \%$, and $28 \%$, respectively, as shown in Table 2.

Table 2. Performance factores

\begin{tabular}{c|c|c|c}
\hline CFRP configuration & Stiffness,kN/mm & Toughness, $\mathbf{k N}$.mm & ductility index \\
\hline Control & 3.8 & 1244 & 4.38 \\
1 strip & 4.8 & 1687 & 3.62 \\
2 strips & 6.3 & 2044 & 3.07 \\
3 strips & 7.4 & 2258 & 2.96 \\
4 strips & 8.4 & 2420 & 2.74 \\
5 strips & 9.9 & 2440 & 2.67 \\
6 strips & 11.4 & 2461 & 2.60 \\
\hline
\end{tabular}

Finally, the toughness is defined as the area under the load-deflection response of slab. The toughness for strengthened slabs with 6 strips, 5 strips, 4 strips, 3 strips, 2 strips, and 1 strip was $2461 \mathrm{kN} . \mathrm{mm}, 2440 \mathrm{kN} . \mathrm{mm}, 2420$ kN.mm, 2258 kN.mm, 2044 kN.mm, 1687 kN.mm, and 1244 N.mm, respectively, which represent an increase in the stiffness with respect to the control slab of $98 \%, 96 \%, 95 \%$, $82 \%, 64 \%$, and $36 \%$, respectively, as shown in Table 2 . The strengthened tested specimen by Alrousan et al, [20] showed a higher load-carrying capacity than those of the control specimens. The average ultimate load of the controlled slabs was $76.5 \mathrm{kN}$, while $109.5 \mathrm{kN}$ strengthened slab. The ultimate load carrying capacities with respect to the control slab increased by $43 \%$ and this enhancement percentage is closed to NLFEA ones. The load-deflection curves reveal that the deflection was decreased with applying the CFRP to the slab. In general, the strengthened specimens experienced smaller deformation than the corresponding control specimens due to the effect of the CFRP sheets on the slabs' overall behavior.

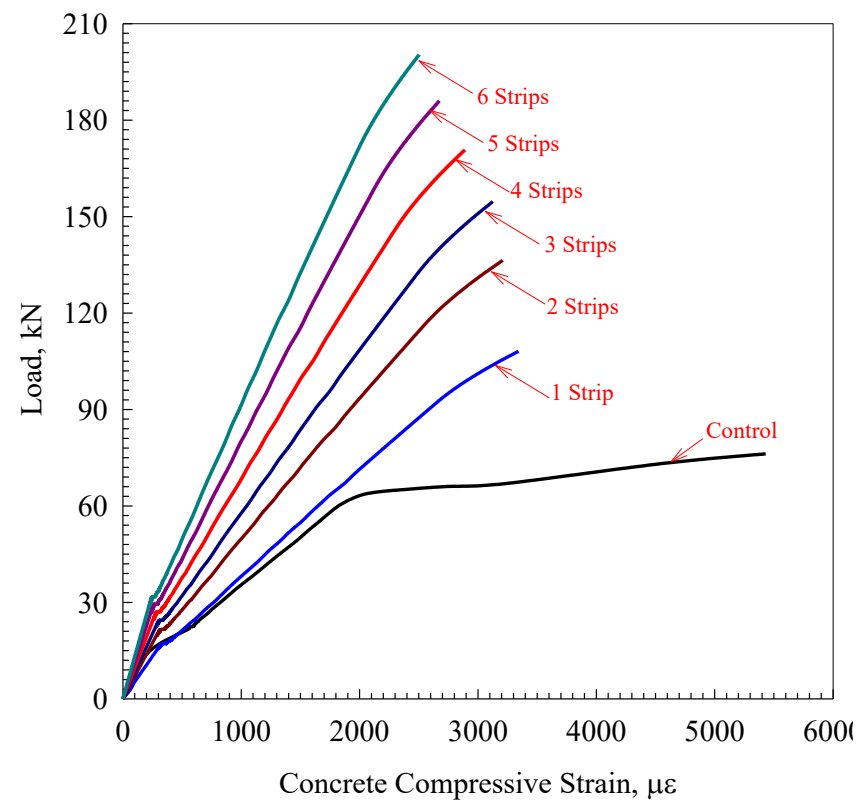

Fig. 6. Load compressive strain responses

\section{c) Load-Strain Response}

For both the control and the strengthened slabs, Figure 6 illustrates the concrete's load-compressive strains in the midspan top and bottom, while Figure 7 illustrates the load-tensile strains. Figure 6 explicitly shows that prior to cracking, the slabs' compressive strains maintained their pattern, and their maximum values were equal to or above $3000 \mu \varepsilon$. When the number of the CFRP layers of CFRP was raised, the concrete strains further reduced. In turn, Figure 7 clearly indicated that the slabs had less levels of strain when the number of CFRP strips was raised. As for the strengthened-with-CFRP slabs, the tensile strains were below the of the CFRP's ultimate strain $(16700 \mu \varepsilon)$. That means that the CFRP sheets had not a tensile failure. For some slabs, the generated-by-NLFEA standard contours of strain, at ultimate, are depicted in Figure 8. For the tested slabs strengthened [20] with CFRP sheet system, the tensile strains did not also exceed the ultimate strain of $16700 \mu \varepsilon$ except the slab strengthened slab. This indicates that no tensile failure of CFRP sheet layers was occurred.

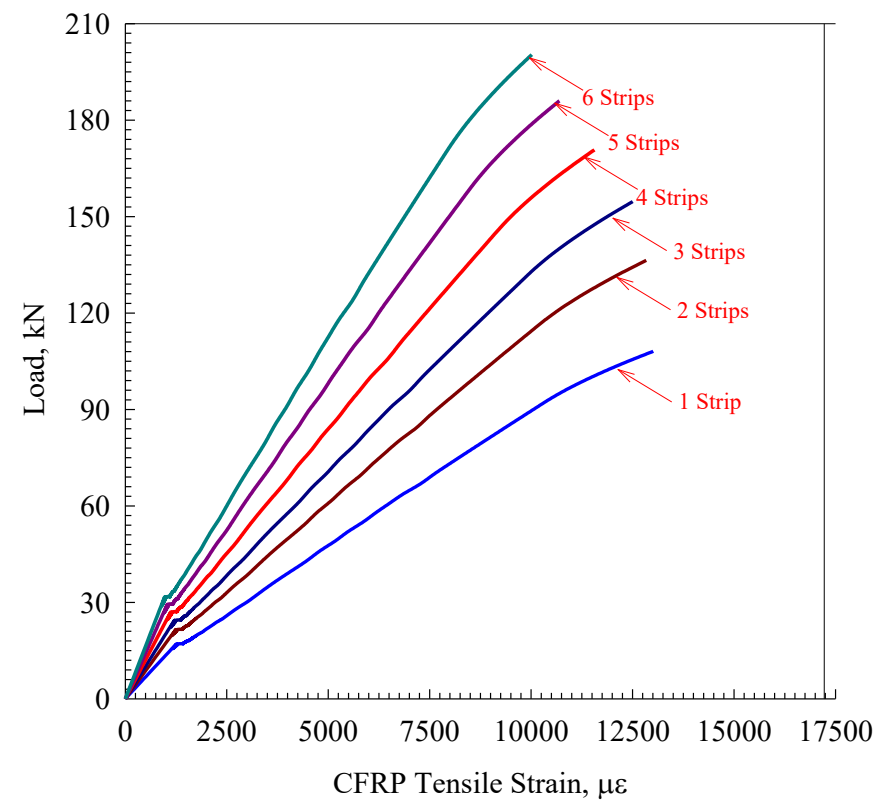

Fig. 7. Load CFRP tensile strain responses

d) Ductility Performance 
The deflection ductility index $\left(\mu_{\Delta}\right)$ was calculated for each slab by dividing the mid-span deflection at ultimate $\left(\Delta_{\mathrm{U}}\right)$ over the mid-span deflection at yielding of the tension steel $\left(\Delta_{\mathrm{y}}\right)$. Table 2 summarizes the deflection ductility of the control and the CFRP-strengthened slabs. The results show that all the CFRP-strengthened specimens experienced lower ductility's than the control specimens. Inspection of Table 2 also reveals that increasing the applied number of CFRP strips leads to a loss in ductility. In conclusion, increasing the applied CFRP to a certain number increases the strengthened reinforced concrete slabs' strength but scarifies the ductility.

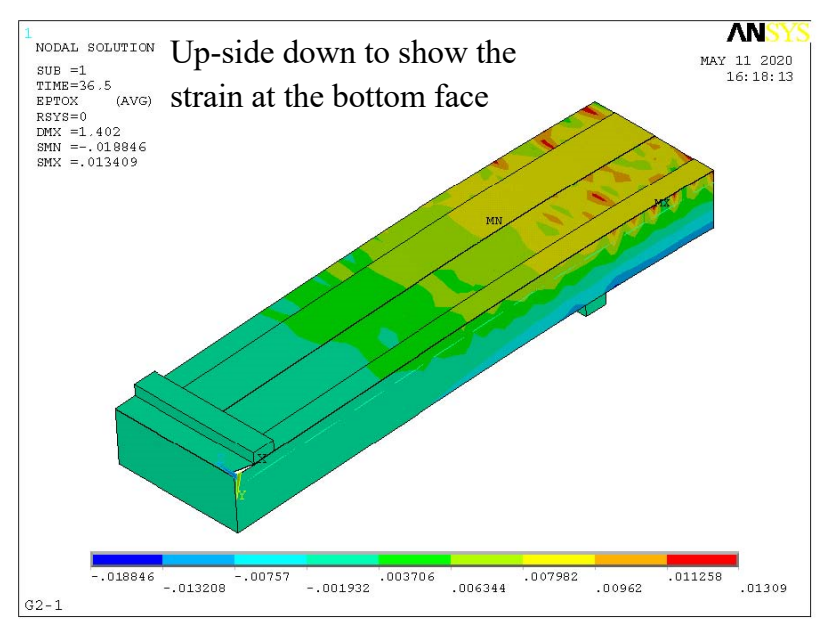

Fig. 8. Strain contours for 3 strips

\section{Conclusions}

Strengthening with externally-bonded CFRP laminates has shown great efficiency in improving the RC slab's ultimate carrying capacity. In the strengthened-with-CFRP slabs, the failure passed through three stages: the first stage began with the reinforcing steel's yielding; then, the CFRP laminates ruptured, partially; and the, in the last stage, the concrete crushed in the compression region. Raising the number of the laminated CFRP sheets/strips resulted in an enhancement in the ultimate load, however disproportionately. On the other hand, when more layers of CFRP were added, the strains of concrete and steel decreased. Additionally, the strength was enhanced when more CFRP layers were added, to a limited extent, without affecting the ductility.

This is an Open Access article distributed under the terms of the Creative Commons Attribution License

\section{References}

1. Al-Rousan, R.Z., Issa, M.A. "The effect of beam depth on the shear behavior of reinforced concrete beams externally strengthened with carbon fiber-reinforced polymer composites." Advances in Structural Engineering, 19(11), p. 769-1779, (2016).

2. Rajai Z. Al-Rousan. "Behavior of macro synthetic fiber concrete beams strengthened with different CFRP composite configurations." Journal of Building Engineering, 20(1), p.595-608, (2018).

3. Rajai Z. Al-Rousan, Mohammad A. Alhassan, Esmail A. AlShuqari. "Shear Nonlinear Behavior of plain concrete beams with DSSF strengthened in flexure with anchored CFRP sheets-Effects of DSSF content on the bonding length of CFRP sheets." Case Studies in Construction Materials, 9(1), p. e195, (2018).

4. Al-Rousan, R. "Empirical and NLFEA prediction of bond-slip behavior between DSSF concrete and anchored CFRP composites." Construction and Building Materials, 169(1), P. 530-542, (2018).

5. Al-Rousan, R.Z., Issa, M.A. "Flexural behavior of RC beams externally strengthened with CFRP composites exposed to severe environment conditions.” KSCE Journal of Civil Engineering, 21(6), p. 2300-2309, (2017).

6. Al-Rousan, R. Z. "Shear behavior of RC beams externally strengthened and anchored with CFRP composites." Structural Engineering and Mechanics, 64(4), p. 447-456, (2017).

7. Erki, M. A., and Heffernan, P. J. "Reinforced Concrete Slabs Externally Strengthened with Fiber-Reinforced Plastic Materials." Proceedings of the Second International RILEM Symposium FRPRCS-2, p. 509-516, (1995).

8. Tamer El Maaddawy, and Khaled Soudki. "Strengthening of reinforced concrete slabs with mechanically-anchored unbonded FRP system." Construction and Building Materials, 22(4), p. 444455, (2008).

9. Scott T. Smith, Shenghua Hu, SeoJin Kim, and Rudolf Seracino. "FRP-strengthened RC slabs anchored with FRP anchors." Engineering Structures, 33(4), p. 1075-1087, (2011).

10. Elgabbas, A.A. El-Ghandour, A.A. Abdelrahman, and A.S. El-Dieb. "Different CFRP strengthening techniques for prestressed hollow core concrete slabs: Experimental study and analytical investigation.” Composite Structures, 92(2), p. 401-411, (2010).

11. Duarte M.V. Faria, Válter J.G. Lúcio, and A. Pinho Ramos. "Strengthening of flat slabs with post-tensioning using anchorages by bonding." Engineering Structures, 33(6), p. 2025-2043, (2011).

12. Arduini, M., Nanni, A., and Romagnolo, M. "Performance of Oneway Reinforced Concrete Slabs with Externally Bonded FiberReinforced Polymer Strengthening." ACI Structural Journal, 101(2), p. 193-201, (2004).

13. Limam, O., Foret, G., Ehrlacher, A. "RC two-way slabs strengthened with CFRP strips: experimental study and a limit analysis approach." Composite Structures, 60(4), p. 467- 471, (2003).

14. Ebead, U., and Marzouk, H. "Fiber-Reinforced Polymer Strengthening of Two-Way Slabs.” ACI Structural Journal, 101(5), p. $650-659,(2004)$.

15. Tan, K. Y., Tumialan, G., and Nanni, A. "Evaluation of Externally Bonded CFRP Systems for The Strengthening of RC Slabs." Department of Civil Engineering, University of Missouri, Rolla, (2003).

16. ACI Committee 318. Building Code Requirements for Structural Concrete. ACI 318-08 and Commentary ACI 318R-08, Michigan: American Concrete Institute, (2008).

17. ANSYS, ANSYS User's Manual Revision 9.0, ANSYS, Inc.

18. William, K. J. and Warnke, E. P. "Constitutive Model for the Triaxial Behavior of Concrete," Proceedings, International Association for Bridge and Structural Engineering, 19, ISMES, Bergamo, Italy, p. 11, (1975).

19. Hemmaty, Y. "Modeling of the Shear Force Transferred Between Cracks in Reinforced and Fiber Reinforced Concrete Structures." Proceedings of the ANSYS Conference, 1(1), p. 13-16, (1998).

20. Alrousan R., Issa M., and Shabila H. "Performance of reinforced concrete slabs strengthened with different types and configurations of CFRP," Composites Part B: Engineering Journal, 43(2), p. 510521, (2012). 